УДК 666.972 .16

DOI https://doi.org/10.32782/2664-0406.2020.38.6

\title{
Шептун С.Ю.
}

к.т.н., доцент кафедры надежности, прочности и технического сервиса машин имени В.Я. Аниловича,

Харьковский национальный технический университет сельского хозяйства имени Петра Василенко, г. Харьков

\section{ВЛИЯНИЕ МИКРОДИСПЕРСНЫХ НАПОЛНИТЕЛЕЙ ИЗ СЫРЬЯ ТЕХНОГЕННЫХ ОТХОДОВ НА АДГЕЗИОННУЮ ПРОЧНОСТЬ НАЛИВНЫХ ПОЛОВ}

\begin{abstract}
Анотація. Упродовж багатьох років стоїть питання про ефективність застосування відходів промисловості у складах сухих будівельних сумішей. Після багаторічної роботи промислових підприємств залишено велику кількість відходів виробничтва, які практично не використовуються. Особливо гострим є питання про використання відходів виробництва на підприємствах феросплавної промисловості. У статті приведені результати впливу відходів виробництва на адгезію до бетонної основи складів на цементній основі для улаштування наливних підлог.

Монолітні безшовні покриття в більшості випадків застосовуються в промислових, сільськогосподарських і громадських (спортивних, навчальних та ін.) будівлях. Підлоги промислових будівель повинні відповідати підвищеним вимогам на опір механічним впливам, а для деяких виробництв - бути хімічно- $і$ теплостійкими $і$ ін. Підлоги щивільних будинків повинні мати необхідну міщність, зносостійкість, пружність, гладку поверхню, невисоку теплопровідність, легко очищатися від забруднень, мати естетичний вигляд і відповідати дизайну інтер'єру.

На съогодні ще немає загальноприйнятої теоріі, яка повністю пояснює процес адгезіі. У зв'язку з різноманітністю явищ, які відбуваються на різних етапах процесу зчеплення матеріалів, створення загальної теорії процесів адгезії значно ускладнене. Жодна з наявних теорій не є універсальною. Водночас не можна віддати перевагу жодній з иих теорій. Кожна з них вносить свій внесок у загальну теорію механізму склеювання.

Для вивчення адгезійних властивостей складу на цементному в'язкому були використані в якості наповнювачів відходи виробничтва: шлам від мокрого газоочищення виробництва феросилічію, шлам водопом'якшення Харківської ТЕЦ - 5 і керамзитовий пил. У результаті було виявлено позитивний та негативний вплив мікронаповнювачів на властивості сухих будівельних сумішей. У статті представлені порівняльні дані щодо міщності адгезї до бетонної основи при додаванні мікронаповнювачів трьох видів, які були вказані вище.

Ключові слова: суха будівельна суміш, наливна підлога, мікронаповнювач, илам, керамзитовий пил, адгезія, відходи виробництва.
\end{abstract}

Постановка проблемы. В последние годы растет потребление таких материалов, как кладочные, выравнивающие и штукатурные составы для внутренних и наружных работ на цементном и гипсовом вяжущем, специальных материалов, таких как клеи, наполнители, армированные растворы, цветные шту- катурные составы и др. Применение сухих строительных смесей заводского изготовления позволяет удовлетворить все более возрастающие требования к качеству и экономичности строительства [1, с. 5].

Применение сухих строительных смесей заводского изготовления для проведения строительных и ремонтных работ 
значительно повышает их продуктивность [2, с. 28].

Пол гражданских и промышленных зданий - это основной элемент конструкций и интерьера здания, который воспринимает эксплуатационные воздействия, на котором осуществляется весь производственный процесс и жизнедеятельность людей.

Основными типами полов являются: бетонные, цементные, асфальтовые, асфальтобетонные, металлические, металлоцементные, мозаичные, каменные, керамические, деревянные и др.

В наше время в конструкции пола выделяют: основание, подстилающий слой [3, с. 20], звукоизоляция, теплоизоляция, стяжка, гидроизоляция, грунтовка, покрытие [4, с. 17].

Существуют следующие типы материалов для покрытий полов: монолитные бесшовные (цементно-бетонные, асфальтобетонные, полимерные мастичные, ксилолитовые, земляные, глинобитные и др.); листовые и рулонные материалы (линолеум, синтетические ворсовые покрытия, сверхтвердые древесноволокнистые плиты и др.); штучные материалы (паркет, доски, керамическая плитка, бетонные и каменные плиты, металлические плиты и др.).

В производственных помещениях часто применяются монолитные покрытия из композиций на цементных вяжущих. Такие покрытия имеют хорошие эксплуатационные характеристиками и сравнительно невысокую стоимость.

Полы должны обладать необходимой прочностью, износостойкостью, упругостью, гладкостью, невысокой теплопроводностью, легко очищаться от загрязнений, иметь эстетичный вид и соответствовать дизайну интерьера.

Анализ последних исследований. На сегодняшний день еще нет общепринятой теории, которая полностью объясняла процесс адгезии. В связи с разнообразностью явлений, которые происходят на разных этапах процесса сцепления материалов, создание общей теории процессов адгезии значительно усложняется.
Одной из первых теорий, которая была предложена для объяснения процесса склеивания, была гипотеза Мак-Бена, которая рассматривает этот процесс как механическое «заклинивание» клеящего вещества в порах материала. Однако, предположения Мак-Бена были опровергнуты в работе. Позже появились мнения про так называемую «специфическую» адгезию. Под адгезией принято понимать сцепление, которое возникает между двумя соприкасающимися материалами. При случае клеевых соединений адгезия - это сцепление между клеящим веществом и поверхностью, которая склеивается. При рассмотрении адгезионных явлений необходимо учитывать и когезию - сцепление в средине склеенных материалов. В настоящий момент наибольшее значение набирают адсорбционная, электрическая, диффузионная и химическая теория адгезии.

Адсорбционная теория адгезии рассматривает создание связи межу клеящим веществом (адгезивом) и материалом (субстратом) как результат действия междумолекулярных сил. Впервые на значение адсорбционных явлений для процесса адгезии было указано [5] еще в 1926 г. Тем не менее основы адсорбционной теории адгезии были разработаны значительно позже Дебройном и Мак-Лареном.

В соответствии с представлениями Мак-Ларена образование клеящего шара происходит в две стадии. На первой стадии происходит перемещение (миграция) молекул адгезива к поверхности субстрата, и полярные группы молекул приближаются к полярным участкам субстрата, на второй стадии наблюдается сорбция. При достаточно близком расстоянии между молекулами адгезива и субстрата начинают действовать молекулярные силы (дисперсные, индукционные, электростатические), которые приводят к образованию разных связей (диполь-диполь, диполь-наведенный диполь, водородная связь и др.).

Электрическая теория адгезии, которую развили Б.В. Дерягин и Н.А. Крото- 
ва, основывается на представлении про двойной электрический шар, который образуется при тесном контакте двух поверхностей.

В.В. Карасев, Н.А. Кротова и Б.В. Дерягин при отрыве клеющих пленок открыли явление электронной эмиссии, которая подтверждает электрическую теорию адгезии.

Электрическая теория адгезии не имеет универсального характера и имеет недостатки. К примеру, с точки зрения только этой теории тяжело объяснить увеличение адгезии в меру сближения природы материалов, которые соединяются один с другим. Если бы все зависело от образования двойного электронного шара, должна была наблюдаться обратная зависимость [6, с. 78].

В соответствии с химической теорией адгезия разных материалов обусловлена образованием химических связей.

Энергия связей наиболее высока в химических, меньшей степенью в водородных, электростатических, дисперсных и инудуктивных связях.

Ни одна из представленных теорий не является универсальной. В то же время нельзя отдать предпочтение ни одной из этих теорий. Каждая из них вносит свой вклад в общую теорию механизма склеивания.

При формировании клеящей пленке происходят усадочные явления, которые приводят к возникновению внутренних напряжений, которые негативно влияют на прочность клеевых соединений.

Многими исследованиями установлено, что с уменьшением толщины клеящей пленки увеличивается прочность клеящего соединения. Тонкий клеящий шар прочней потому, что вероятность появления в нем дефектов меньше, чем в более толстом клеевом шаре. Влияние толщины клеящего шара на прочность связана с одновременным действием двух факторов пластической текучести и внутренних напряжений [7, с. 28].

Наряду с введением полимерных добавок известен ряд способов улучше- ния клеящей способности цементного камня. Один из них основан на концепции, которая рассматривает цементный камень как микробетон. В соответствии с этой концепцией рационально повышать дисперсность цементного клея, обеспечивая его полную гидратацию. Зерна цемента крупностью больше 40 мкм, которые практически не гидратируются, рационально заменить наполнителями. На этой концепции основываются технологии сухого и мокрого помола цемента вместе с песком и другими наполнителями, в результате чего получается коллоидный цементный клей. Помол цемента не получил распространения в связи с высокой энергоемкостью, несовершенной конструкцией помольных агрегатов и быстрой потерей активности [8, с. 61].

Значительное развитие получили исследования по активации цементного вяжущего, а также смеси цемента с наполнителями. К наполнителям относят порошкоподобные или волокнистые материалы, которые применяют для экономии вяжущего и регулирования физико-технических свойств композиционных материалов, в том числе строительных [9, с. 156$]$.

Зола уноса активно влияет на всех стадиях гидратации и структурообразования цементных систем, формирование структуры композиционных строительных материалов, то есть последовательного перехода от коагуляционной структуры к образованию пространственного кристаллического каркаса. Введение золы-уноса в растворные смеси в качестве активного наполнителя является известным технологическим приемом, который направлен на снижение расхода цемента и извести [9, с. 157].

Введение карбонатного наполнителя увеличивает, как и зольный наполнитель, объем гидратных новообразований, что также позитивно влияет на величину адгезионной прочности растворов. Увеличение содержания карбонатной пыли до 
15\% от массы цемента приводит к увеличению адгезионной прочности на $16 . . .33 \%$ во все сроки твердения [10, с. 89].

Дополнительным фактором, который способствует увеличению адгезионной прочности, служит увеличение дисперсности золы-уноса. Так, помол золы до удельной поверхности $390 \mathrm{~m}^{2} /$ кг позволяет увеличить прочность сцепления раствора с основой в возрасте 7 суток на $14 . .26 \%$, в возрасте 28 суток - на $13 . . .18 \%$. [10, c. 94$]$.

Цели работы. Целью исследования является увеличение адгезии раствора сухой строительной смеси к бетону за счет использования отходов производства.
Использование отходов производства таких, как шлама от мокрого газоочищения производства ферросилиция и керамзитовой пыли, должно не только удешевить себестоимость смесей, но и способствовать решению экологических проблем.

Результаты исследований. На основе проведенного анализа можно предположить, что для улучшения физико-технических свойств сухих строительных смесей возможно использовать тонкодисперсные наполнители, в частности: шлам от мокрого газоочищения производства ферросилиция, керамзитовую пыль, получаемую при обжиге керамзитового гравия; шлам водоумягчения ТЭЦ - 5.

Таблица 1. Химический состав шлама

\begin{tabular}{|c|c|c|c|c|c|c|c|c|c|c|c|}
\hline \multirow{2}{*}{$\begin{array}{c}\text { Наименование } \\
\text { шлама }\end{array}$} & \multicolumn{7}{|c|}{ Содержание компонентов, \% } \\
\cline { 2 - 11 } & $\mathrm{SiO}_{2}$ & $\mathrm{Fe}_{3} \mathrm{O}_{4}$ & $\mathrm{Al}_{2} \mathrm{O}_{3}$ & $\mathrm{CaO}$ & $\mathrm{MgO}$ & $\mathrm{K}_{2} \mathrm{O}$ & $\mathrm{Na}_{2} \mathrm{O}$ & $\mathrm{TiO}$ & $\mathrm{P}_{4} \mathrm{O}_{10}$ & $\mathrm{MnO}$ & $\begin{array}{c}\text { п. П. } \\
\text { п. }\end{array}$ \\
\hline $\begin{array}{c}\text { Более } 20 \text { лет } \\
\text { хранения после } \\
\text { производства }\end{array}$ & 81,3 & 3,6 & 3,5 & 1,2 & 1,0 & 0,9 & 0,65 & 0,1 & 0,03 & 0,01 & 7,71 \\
\hline
\end{tabular}

Таблица 2. Адгезионная прочность разработанных составов

\begin{tabular}{|c|c|c|c|c|c|}
\hline Цемент Пц-500 & \multicolumn{5}{|c|}{33} \\
\hline Песок & \multicolumn{5}{|c|}{65} \\
\hline Пластификатор Sika & \multicolumn{5}{|c|}{0,5} \\
\hline Мод цел Bermocoll & \multicolumn{5}{|c|}{0,01} \\
\hline $\begin{array}{c}\text { Редиспергируемый } \\
\text { порошок }\end{array}$ & \multicolumn{5}{|c|}{1,49} \\
\hline $\begin{array}{l}\text { Шлам } 25 \text { лет } \\
\text { \% от цемента }\end{array}$ & $15 \%$ & $15 \%$ & $15 \%$ & $15 \%$ & $15 \%$ \\
\hline Керамзит \% от цемента & - & - & - & $5 \%$ & $10 \%$ \\
\hline $\begin{array}{l}\text { Шлам ТЭЦ-5 } \\
\text { \% от цемента }\end{array}$ & - & $5 \%$ & $10 \%$ & - & - \\
\hline Вода В/Ц & 0,5 & 0,6 & 0,6 & 0,6 & 0,6 \\
\hline \multicolumn{6}{|c|}{ Прочность сцепления с бетонным основанием } \\
\hline Здн $\left(\right.$ кгс $\left./ \mathrm{cm}^{2}\right)$ & 5,0 & 5,0 & 3,0 & 6,0 & 6,0 \\
\hline 7 дн $\left(\kappa г с / \mathrm{cm}^{2}\right)$ & 8,0 & 5,0 & 2,0 & 4,5 & 8,0 \\
\hline 14дн $\left(\right.$ кгс $\left./ \mathrm{cm}^{2}\right)$ & 5,0 & 5,0 & 3,0 & 6,0 & 6,0 \\
\hline 28 дн $\left(\right.$ кгс $\left./ \mathrm{cm}^{2}\right)$ & 10,5 & 10,5 & 9,0 & 14,0 & 13,0 \\
\hline
\end{tabular}


Шлам от мокрого газоочищения образуется при выплавке ферросилиции во время очистки исходящего ферросплавного газа от пыли по технологии мокрой газоочистки. В ходе этого процесса образуется пульпа, которая транспортируется по трубопроводам в шламонакопители.

Однако нельзя использовать шлам прямо из отвалов. На протяжении многих лет складирования он, под воздействием атмосферных явлений, набирался влаги и собирался в комья. Поэтому его необходимо измельчить. Измельчение шлама проводился на дезинтеграторе после предварительной его сушки в электрическом сушильном шкафу. В результате измельчения был получен микронаполнитель со средней плотностью 180-250 кг $/ \mathrm{m}^{3}$ и удельной поверхностью 15000-25000 см²/г. Химический состав шлама от мокрых газоочисток производства ферросилиция представлен в таблице 1.

Керамзитовая пыль - отход керамзитового производства, получаемый при обжиге керамзитового гравия. Представляет собой мелкодисперсный коричневого цвета кремнеземсодержащий материал, обладающий свойствами активных минеральных добавок, плотностью 2,6 г $/ \mathrm{cm}^{3}$ и удельной поверхностью 2500-4000 $\mathrm{cm}^{2} /$ г.

Ведение в сухую строительную смесь керамзитовой пыли способствует повышению пластичности растворной смеси, облегчает нанесение смесей на покрываемую поверхность и решает проблему утилизации техногенного отхода производства. На больших керамзитовых заводах ежесуточно может образовываться до 7-8 тонн керамзитовой пыли, чаще всего, которая вывозиться на свалку.

Минеральный модификатор в виде шлама водоумягчения Харьковской ТЭЦ 5 благодаря своей дисперсности (более $2870 \mathrm{~cm}^{2} /$ г) и своеобразию структуры частиц позволяет значительно улучшить эффективность работы пластификато- ра, модифицированной целлюлозы и редиспергируемого сополимерного порошка. Химический состав шлама водоумягчения ТЭЦ - 5 следующий: $\mathrm{CaCO}_{3}-58,2 \%$, портландита - 33,4 \%, остальное примеси.

Составы сухих строительных смесей, на которых проводилась оценка влияния сочетаний шлама от мокрого газоочищения производства ферросилиция, керамзитовой пыли и шлама водоумягчения Харьковской ТЭЦ -5 на адгезию, представлены в таблице 2.

Из полученных результатов видно, позитивное влияние совместного добавления шлама от мокрого газоочищения и керамзитовой пыли. Однако добавление шлама от мокрого газоочищения производства ферросилиция и шлама водоумягчения ТЭЦ не продемонстрировало положительных результатов.

Повышение адгезии цементного раствора к бетону образцов с содержанием керамзитовой пыли достигается за счет увеличения однородности цементного камня.

Введение шлама водоумягчения может иметь негативное влияние на сопротивление цементного раствора к истиранию в связи с тем, что кальцит имеет низкую твердость по сравнению с твердостью кварца (основного компонента шлама от мокрого газоочищения производства ферросилиция) в соответствии со шкалой Мооса. Поэтому ему сложнее противостоять истиранию.

Выводы. Благодаря использованию керамзитовой пыли прочность сцепления между бетонным основанием и разработанным составом покрытия пола возросла на $23-33 \%$.

C добавлением керамзитовой пыли и шлама от мокрых газоочисток производства ферросилиция увеличивается контактная зона между заполнителем и цементным камнем. В результате чего увеличивается адгезионная прочность. Применение шлама водоумягчения Харьковской ТЭЦ - 5 не дало позитивного эффекта на прочность адгезии. 


\section{Лuтература}

1. Рекитар Я.А. Долговременные тенденции развития производства строительных материалов и инвестиционная политика в этой области. Строительные материалы, оборудование, технологии ХХІ века. 2001 г. № 7. С. 4-6.

2. Макаревич М.С. Сухие строительные смеси для штукатурных работ с тонкодисперсными минеральными добавками : дис. на соиск. учен. степ. канд. техн. наук : спец. 05.23.05. Томск, 2005 г. 180 c.

3. Стасенко Ю.М. Современные напольные покрытия. Строительные материалы, оборудование технологии ХХІ века. 2004. № 1. С. 20-21.

4. Голенковская В.А. Устройство наливных полов с применением сухих строительных смесей. Строительные материалы. 2000. № 1. С. 16-17.

5. Bancroft M.D., Applied Colloid Chemistry, McGrow. Hill, New York, 1926. P. 81.

6. Москвин Н.И. Физико-химические основы процессов склеивания и прилипания. Изд. «Лесная промышленность», 1964. 248 с.

7. Калашников В.И. Баженов Ю.М., Демьянов В.С. Влияние СП на твердение цемента. Строительные материалы, оборудование и технологии ХХІ века. 2001. № 1. С. 28-29.

8. Соломатов В.И., Дворкин Л.И., Чудновский С.М. Пути активизации наполнителей композиционных строительных материалов. Изв. вузов: Строительство и архитектура. 1987. № 1. С. $60-63$.

9. Соломатов В.И., Сецев В.П. Химическое сопротивление композиционных строительных материалов. Москва : Стройиздат, 1987. 264 с.

10. Дворкін Л.Й., Дворкін О.Л., Гарніцький Ю.В. Модифіковані золовмісні сухі будівельні суміші для мурувальних та клейових розчинів: монографія. Рівне : НУВГП, 2013. 219 с.

\section{References}

1. Rekitar Ya. A. Dolgovremennyie tendentsii razvitiya proizvodstva stroitelnyih materialov i investitsionnaya politika v etoy oblasti. Stroitelnyie materialyi, oborudovanie, tehnologii XXI veka. 2001 g. №7. S. 4-6

2. Makarevich M. S. Suhie stroitelnyie smesi dlya shtukaturnyih rabot s tonkodispersnyimi mineralnyimi dobavkami: dis. na soisk. uchen. step. kand. tehn. nauk: spets. 05.23.05. Tomsk, 2005. $180 \mathrm{~s}$.

3. Stasenko Yu. M. Sovremennyie napolnyie pokryitiya. Stroitelnyie materialyi, oborudovanie tehnologii XXI veka. 2004. №1. S. 20-21.

4. Golenkovskaya V. A. Ustroystvo nalivnyih polov s primeneniem suhih stroitelnyih smesey. Stroitelnyie materialyi. 2000. №1. S. 16-17.

5. 5. Bancroft M.D., Applied Colloid Chemistry, McGrow. Hill, New York, 1926. S.81.

6. Moskvin N.I. Fiziko-himicheskie osnovyi protsessov skleivaniya i prilipaniya. Izd. «Lesnaya promyishlennost», 1964. $248 \mathrm{~s}$.

7. Kalashnikov V. I., Bazhenov Yu. M., Demyanov V. S. Vliyanie SP na tverdenie tsementa. Stroitelnyie materialyi, oborudovanie i tehnologii HHI veka. 2001, №1. S. 28-29.

8. Solomatov V.I., Dvorkin L.I., Chudnovskiy S. M. Putiaktivizatsii napolniteley kompozitsionnyih stroitelnyih materialov. Izv. vuzov: Stroitelstvo i arhitektura. 1987. N1. S. $60-63$.

9. Solomatov V. I., Setsev V. P. Himicheskoe soprotivlenie kompozitsionnyih stroitelnyih materialov. Moskva: Stroyizdat, 1987. 264 s.

10. Dvorkin L. Y., Dvorkin O. L. Modyfikovani zolovmisni sukhi budivelni sumishi dlia muruvalnykh ta kleiovykh rozchyniv: monohrafiia. Rivne : NUVHP, 2013. 219 s. 


\title{
THE EFFECT OF MICRODISPERSION FILLERS FROM RAW MATERIALS OF INDUSTRIAL WASTE ON THE ADHESIVE STRENGTH OF SELF-LEVELLING FLOORS
}

\begin{abstract}
For many years, there has been a question about the possibility of using industrial waste in the composition of dry building mixtures. After many years industrial enterprises formed a large amount of production waste, which is practically not used in any way. Utilization of the production waste of the ferroalloy industry is especially acute. The article presents the results of the influence of production waste on the adhesive properties of $c e$ ment-based compositions for the installation of self-levelling floors.

Monolithic seamless coatings in most cases are used in industrial, agricultural and public (sports, educational, etc.) buildings. The floors of industrial buildings must meet increased requirements for resistance to mechanical stress, and for some industries - for chemical resistance, heat resistance, etc. The floors of civil buildings must have the necessary strength, resistance, elasticity, smoothness, low thermal conductivity, be easy to clean from dirt, have an aesthetic appearance and match the interior design.

To date, there is still no generally accepted theory that fully explains the adhesion process. Due to the variety of phenomena that occur at different stages of the adhesion process of materials, the creation of a general theory of adhesion processes is significantly complicated. None of the existing theories are universal. Each of them contributes to the general theory of the adhesive mechanism.

To study the adhesive properties of the composition on a cement binder, production wastes were used as fillers: wet gas cleaning sludge from the production of ferrosilicon, sludge water softening of Kharkiv CHP - 5 and expanded clay dust. As a result, the positive and negative influence of microfillers on the properties of dry building mixtures was revealed. The article presents comparative data on the adhesion strength when adding microfillers of three types, which were mention above.
\end{abstract}

Key words: dry mortar, self-leveling floor, adhesion, waste production.

Sheptun S.Yu.

Ph.D., Associate Professor at the Department of Reliability, Strength and Technical Service of Machines named after V.Ya. Anilovich, Kharkiv Petro Vasylenko National Technical University of Agriculture, Kharkiv 